\title{
Tamoxifen Induces Vasorelaxation via Inhibition of Mitogen-Activated Protein Kinase in Rat Aortic Smooth Muscle
}

\author{
Sohyun PARK ${ }^{1)}$, Bokyung KIM ${ }^{2) *}$, Junghwan $\mathrm{KIM}^{2)}$, Kyung-Jong WON ${ }^{1)}$, Sangmok $\mathrm{LEE}^{1)}$, Seongchun $\mathrm{KWON}^{3)}$ and \\ SungIl $\mathrm{CHO}^{2)}$ \\ ${ }^{1)}$ Department of Veterinary Physiology, College of Veterinary Medicine, Konkuk University, Seoul 143-701, ${ }^{2)}$ Department of Physiology, \\ College of Medicine, Konkuk University, Choongju 380-701 and ${ }^{3)}$ Department of Physiology, Kwandong University College of Medicine, \\ Kangnung 210-701, Korea
}

(Received 6 May 2003/Accepted 1 July 2003)

ABSTRACT. The contribution of the mitogen-activated protein kinase (MAPK) pathway to the relaxation induced by tamoxifen, a synthetic non-steroidal anti-estrogen, was examined in rat vascular smooth muscle. Tamoxifen $(0.1-300 \mu \mathrm{M})$ inhibited the contraction induced by endothelin-1 (ET-1, $3 \mathrm{nM}$ ) in aortic smooth muscle in a concentration-dependent manner. The inhibitory effect of tamoxifen wa s not attenuated by $10 \mu \mathrm{M}$ ICI 182,780 , a selective antagonist of estrogen receptors. In the $\mathrm{Ca}^{2+}$ channel inhibitor verapamil ( $\left.1 \mu \mathrm{M}\right)$-pretreated strips, tamoxifen also inhibited the contraction induced by ET-1. Both PD098059 and SB203580, inhibitors of MAPK/extracellular signal-regulated kinase (ERK) kinase and p38 MAPK, respectively, inhibited ET-1-induced contraction in aortic smooth muscle. In Western blot analysis with anti-phosphorylated MAPK antibodies, ET-1 (3 nM) enhanced activities of both ERK1/2 and p38 MAPK in aortic muscle strips, which were not attenuated by the treatment with 4 mM EGTA. Tamoxifen $(100 \mu \mathrm{M})$ inhibited the activities of ERK1/2 and p38 MAPK induced by ET-1 without significant changes in the expression of these kinases. These results suggest that tamoxifen nduces relaxation of rat vascular smooth muscle, and that this is, at least in part, mediated by the inhibition of the $\mathrm{Ca}^{2+}$-independent MAPK pathway.

KEY WORDS: endothelin-1, MAPK, relaxation, tamoxifen, vascular smooth muscle.

J. Vet. Med. Sci. 65(11): 1155-1160, 2003

Tamoxifen is a synthetic non-steroidal anti-estrogen that has a role similar to estrogen, including vasorelaxation and maintaining bone density [21]. Tamoxifen may protect against cardiovascular diseases by exerting beneficial effects, such as modifying of the composition of serum lipoprotein levels [26], reducing homocysteine levels [2], and reducing oxidation of low-density lipoproteins [32]. Furthermore, tamoxifen has been shown to inhibit the contractile response of vascular smooth muscle, which may partially account for the reduction in cardiovascular risk [20]. Tamoxifen also inhibits $\mathrm{Ca}^{2+}$ influx, which may be one mechanism underlying the inhibitory effects of this agent on vascular smooth muscle contraction [28].

Smooth muscle contraction is initially triggered by an increase in intracellular $\mathrm{Ca}^{2+}\left(\left[\mathrm{Ca}^{2+}\right]_{\mathrm{i}}\right)$. Agonistic stimuli and high-level $\mathrm{K}^{+}$increase $\left[\mathrm{Ca}^{2+}\right]_{\mathrm{i}}$ and result in an initiation of signal transduction in intracellular spaces. The increased $\left[\mathrm{Ca}^{2+}\right]_{\mathrm{i}}$ binds to calmodulin, a $\mathrm{Ca}^{2+}$-binding protein, and subsequently activates myosin light chain kinase (MLCK), which results in the phosphorylation of myosin light chain (MLC) and force development [12,13]. However, the increase in $\left[\mathrm{Ca}^{2+}\right]_{\mathrm{i}}$ usually involves the activation of intracellular protein kinase pathways. There are several families of protein kinases activated by $\left[\mathrm{Ca}^{2+}\right]_{\mathrm{i}}$ in smooth muscle cells, including protein kinase $\mathrm{C}(\mathrm{PKC})$ and mitogen-activated protein kinase (MAPK), and these kinases are believed to play important roles in vascular contraction [16].

\footnotetext{
* Correspondence to: Kim, B., Department of Physiology, College of Medicine, Konkuk University, Choongju 380-701, Korea.
}

MAPK is a family of serine/threonine-specific protein kinases, consisting of three isoforms: extracellular signalregulated kinase (ERK), p38 MAPK, and stress-activated protein kinase (SAPK)/c-Jun N-terminal kinase (JNK) [22, 31]. ERK $1 / 2$ is activated by receptor agonists, including angiotensin II, phenylephrine, and endothelin-1 (ET-1), which induce smooth muscle contraction [3, 4, 18, 29, 33]. There is accumulating evidence that the p38 MAPK pathway, as well as ERK1/2, is closely linked to the modulation of the intensity of contraction in vascular smooth muscle $[19,24]$. Estrogen inhibits the contraction and MAPK activity in vascular smooth muscle [10], which may result in its protective action on the cardiovascular system. Therefore, it can be assumed that tamoxifen acts on the MAPK pathway and tamoxifen-induced vasorelaxation is mediated by the inhibition of MAPK. However, the effect of tamoxifen on the MAPK pathways has not been elucidated in vascular smooth muscle.

In the present study, we determined whether tamoxifen induces vasorelaxation via inhibition of the MAPK pathway in rat vascular smooth muscle.

\section{MATERIALS AND METHODS}

Preparation of muscle strips and measurement of isometric contraction: All experiments were performed in accordance with the institutional guidelines of Konkuk University, Seoul, Korea. Male Sprague-Dawley rats (190$200 \mathrm{~g}$ ) were used for this study. Rats were stunned and bled; the thoracic aorta was isolated, and cut into strips (2-3 mm 
wide). The endothelium was removed by gently rubbing the inner surface of the vessel with a cotton thread moistened with physiological salt solution (in $\mathrm{mM}$ : $\mathrm{NaCl} \mathrm{136.9,} \mathrm{KCl}$ 5.4, $\mathrm{CaCl}_{2}$ 1.5, $\mathrm{MgCl}_{2}$ 1.0, $\mathrm{NaHCO}_{3} 23.8$, glucose 5.5, and EDTA 0.01). Strips were attached to a holder with a resting tension of $10 \mathrm{mN}$. After equilibration for $20 \mathrm{~min}$ in a physiological salt solution, strips were repeatedly exposed to a $70 \mathrm{mM} \mathrm{K}^{+}$solution until the response became stable. The high concentration of $\mathrm{K}^{+}$was prepared by replacing the $\mathrm{NaCl}$ in the physiological salt solution with equimolar amount of $\mathrm{KCl}$. These solutions were saturated with a mixture of $95 \% \mathrm{O}_{2}$ and $5 \% \mathrm{CO}_{2}$ at $37^{\circ} \mathrm{C}$ and $\mathrm{pH} \mathrm{7.4.} \mathrm{Muscle}$ contraction was recorded isometrically with a force-displacement transducer (FT03, Grass, RI, U.S.A.) connected to a recording system (ADInstrument, Sydney, Australia) [17].

Measurement of MAPK activity: Aortic strips were isolated and prepared as described for the contraction measurement experiments and were snap-frozen in liquid $\mathrm{N}_{2}$ after treatment with various stimulants for different times. The strips were then homogenized in sample buffer containing $50 \mathrm{mM}$ Tris- $\mathrm{HCl}$ (pH 7.4), $5 \mathrm{mM}$ EGTA, $20 \mathrm{mM} \beta$-glycerophosphate, $1 \mathrm{mM} \mathrm{NaF}, 2 \mathrm{mM} \mathrm{Na} \mathrm{VO}_{4}, 5 \mu \mathrm{g} / \mathrm{ml}$ aprotinin, 5 $\mu \mathrm{M}$ leupeptin, $1 \%$ Triton-X 100, $10 \%$ glycerol, $300 \mu \mathrm{M}$ phenylmethylsulfonyl fluoride, $5 \mathrm{mM}$ dithiothreitol, and $150 \mathrm{mM} \mathrm{NaCl}$. The homogenate was centrifuged at 14,000 $\times \mathrm{g}$ for $10 \mathrm{~min}$ at $4^{\circ} \mathrm{C}$ and the supernatant was collected [4, 14, 19]. Protein concentrations were determined using a protein assay kit (BioRad, Hercules, CA, U.S.A.), utilizing a colorimetric assay. Samples were diluted 1:1 (vol:vol) with sodium dodecyl sulfate (SDS) sample buffer containing 40 mM Tris- $\mathrm{HCl}$ (pH 6.8), 8 mM EGTA, 4\% 2-mercaptoethanol, $40 \%$ glycerol, $0.01 \%$ bromophenol blue, and $4 \%$ SDS, and then boiled for $5 \mathrm{~min}$. Equal amounts (30-50 $\mu \mathrm{g} /$ lane) of protein were separated on a $10 \%$ SDS-polyacrylamide gel. Electrophoretically separated proteins were transferred to a polyvinylidene fluoride membrane (Amersham, Buckinghamshire, U.K.). Membranes were incubated for $60 \mathrm{~min}$ in phosphate-buffered saline containing $0.1 \%$ Tween 20 and $5 \%$ non-fat dried milk, then incubated with individual rabbit anti-MAPK antibodies diluted 1:1,000-5,000 overnight at $4^{\circ} \mathrm{C}$. Following incubation with horseradish peroxidase-conjugated anti-rabbit $\operatorname{IgG}(1: 1,000)$ for $60 \mathrm{~min}$, blots were developed using an enhanced chemiluminescence detection system (Amersham). Antibodyspecific bands were quantified using an image analyzer (BioRad).

Materials: Polyclonal anti-phosphorylated and anti-nonphosphorylated ERK1/2 antibodies, Triton-X 100, and dithiothreitol were purchased from Promega (Madison, WI, U.S.A.). Polyclonal anti-phosphorylated and anti-nonphosphorylated p38 MAPK antibodies were purchased from Cell Signaling (Beverly, MA, U.S.A.). ET-1, $17 \beta$-estradiol, verapamil, $\mathrm{NaF}, \beta$-glycerophosphate, $\mathrm{Na}_{3} \mathrm{VO}_{4}$, aprotinin, leupeptin, and phenylmethylsulfonyl fluoride were purchased from Sigma (St. Louis, MO, U.S.A.). Tamoxifen, ICI 182,780, PD098059, and SB203580 were purchased from
Tocris (Bristol, U.K.).

Data analysis: The results of experiments are expressed as means \pm S.E.M. Unpaired Student's $t$-tests were used to compare the data of two groups. Values were considered significantly different at $P<0.05$.

\section{RESULTS}

Effects of tamoxifen on ET-1-induced contractions: Treatment with $3 \mathrm{nM}$ ET-1 increased muscle contraction in rat aortic muscle strips. The maximal contraction obtained by $3 \mathrm{nM} \mathrm{ET-1}$ was $65.7 \pm 5.6 \%(n=10)$ of the $70 \mathrm{mM} \mathrm{K}{ }^{+}$ induced contraction. Tamoxifen inhibited the contraction induced by ET-1 in a concentration-dependent manner (Fig. 1). Tamoxifen at $1 \mu \mathrm{M}$ and $100 \mu \mathrm{M}$ did not evoke any changes in the basal tone of muscle strips (data not shown, $n=4)$. ET-1 (3 nM)-induced contraction was reduced by the pretreatment with the $\mathrm{Ca}^{2+}$ channel inhibitor verapamil 1 $\mu \mathrm{M}$ for $30 \mathrm{~min}\left(28.6 \pm 1.8 \%\right.$ of the $70 \mathrm{mM} \mathrm{K}^{+}$-induced con-

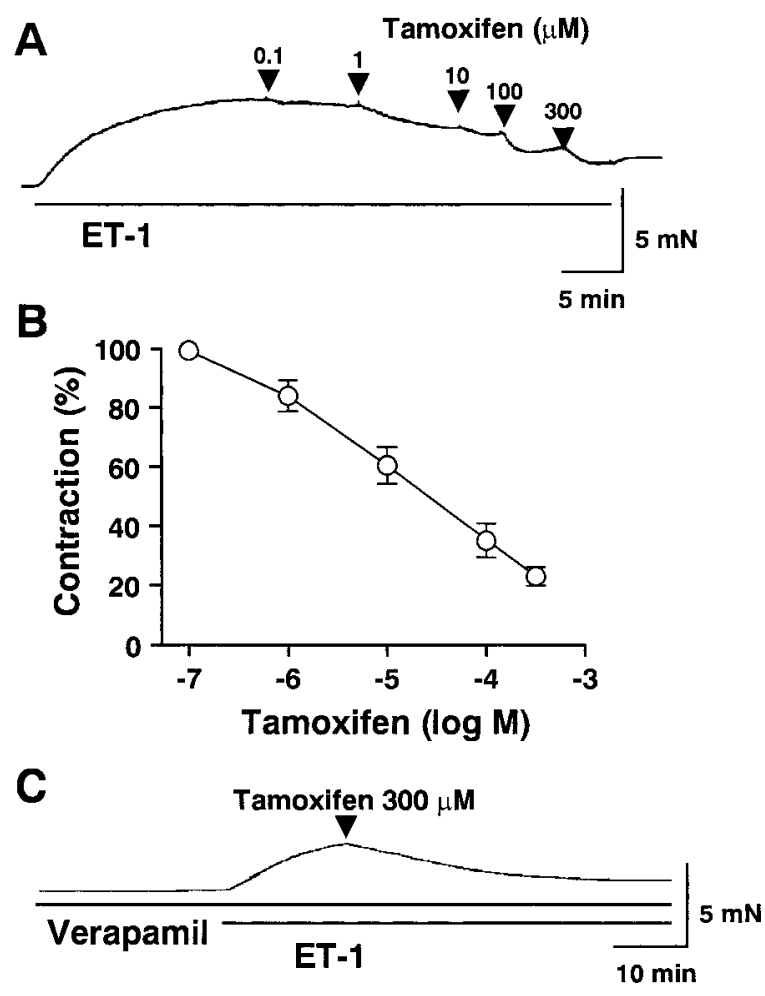

Fig. 1. Effects of tamoxifen on ET-1-induced contraction in rat aortic smooth muscle. (A) Aortic strips were repeatedly stimulated with $70 \mathrm{mM} \mathrm{K}{ }^{+}$and then contracted with ET-1 $(3 \mathrm{nM})$, and tamoxifen $(0.1-300 \mu \mathrm{M})$ were then applied cumulatively. (B) Concentration-dependent responses to tamoxifen on the contraction induced by ET- 1 . The maximum contraction of ET-1 before the application of tamoxifen was defined as $100 \%$. Each point represents the mean \pm S.E.M. of 10 experiments. (C) Strips were treated with $1 \mu \mathrm{M}$ verapamil for $30 \mathrm{~min}$ and then contracted with ET-1 ( $3 \mathrm{nM})$, and tamoxifen was then added cumulatively. Typical recordings obtained from 4 independent experiments. 
traction, $n=4)$, and the contraction was inhibited by the treatment of $300 \mu \mathrm{M}$ tamoxifen in rat aortic muscle strips (Fig. $1 \mathrm{C})$.

Effects of inhibitors on ET-1-induced contractions: To determine whether tamoxifen-induced inhibition is mediated by an estrogen receptor pathway, the effect of estrogen receptor antagonists on the inhibition was determined. Aortic smooth muscle was pretreated with the selective estrogen receptor antagonist ICI 182,780 $(10 \mu \mathrm{M})$ for $20 \mathrm{~min}$ and then stimulated with $3 \mathrm{nM}$ ET-1, and tamoxifen (or $17 \beta$ estradiol) was then added cumulatively. ICI $182,780 \mathrm{did}$ not affect the basal tone of muscle strips. Tamoxifen (0.1-100 $\mu \mathrm{M})$ inhibited the ET-1-induced contraction in the ICI 182,780-pretreated strips, and the inhibition was not significantly different from control (Fig. 2A). In contrast, treatment with $17 \beta$-estradiol $(0.1-100 \mu \mathrm{M})$ also inhibited the contraction elevated by $3 \mathrm{nM}$ ET- 1 in a concentrationdependent manner. The inhibitory effect of $17 \beta$-estradiol was significantly reversed by pretreatment with ICI 182,780 (Fig. 2B). To determine the involvement of the MAPK pathway in ET-1-induced responses, inhibitors of the MAPK pathway were tested by examining their effect on the contraction of aortic smooth muscle. As shown in Fig. 2C, PD098059 (0.1-100 $\mu \mathrm{M})$, an inhibitor of MAPK/ERK kinase, was found to inhibit the contraction induced by $3 \mathrm{nM}$ ET-1 in a concentration-dependent manner. SB203580 (0.1-100 $\mu \mathrm{M})$, an inhibitor of p38 MAPK, inhibited the ET1 -induced contraction in the strips (Fig. 2C).

Effect of tamoxifen on MAPK activity: We examined the effects of tamoxifen on the activities of ERK1/2 and p38 MAPK. The activity of MAPK was measured in rat aortic smooth muscle using Western blot analysis with anti-phosphorylated MAPK antibodies. ET-1 (3 nM) increased the phosphorylation of ERK1/2, which reached a maximum at $15 \min (172.2 \pm 13.9 \%$ of control, $n=4, P<0.05)$, and this high-level was retained for $60 \mathrm{~min}$. Treatment with tamoxifen $(100 \mu \mathrm{M})$ for 45 min reversed the ET-1-induced phosphorylation of ERK1/2 to the non-stimulated levels (109.5 \pm $8.4 \%$ of control, $n=4, P>0.05)$. In the absence of ET-1, tamoxifen $(100 \mu \mathrm{M})$ did not induce any changes of ERK1/2 phosphorylation (Fig. 3). EGTA (4 mM) did not alter the activity of ERK1/2 increased by 3 nM ET-1 (Fig. 3C). The total expression of ERK1/2, determined using an anti-nonphosphorylated ERK1/2 antibody, was not altered by the treatment with ET-1 or tamoxifen (Fig. 3A). ET-1 (3 nM) also increased the phosphorylation of p38 MAPK, with maximal phosphorylation being obtained at $15 \mathrm{~min}(258.5 \pm$ $61.4 \%$ of control, $n=4, P<0.05$ ) and the level being reduced at $60 \mathrm{~min}(211.6 \pm 56.4 \%$ of control, $n=4, P>0.05)$. Tamoxifen $(100 \mu \mathrm{M})$ inhibited the phosphorylation of p38 MAPK induced by ET- 1 in aortic smooth muscle $(101.2 \pm 14.9 \%$ of control, $n=4, P>0.05)$. In the absence of ET-1, tamoxifen $(100 \mu \mathrm{M})$ did not induce any changes of p38 MAPK phosphorylation (Fig. 4). Treatment with EGTA (4 mM) did not alter the activity of p38 MAPK induced by 3 nM ET-1 (Fig. 4C). The total expression of p38 MAPK, using an anti-non-
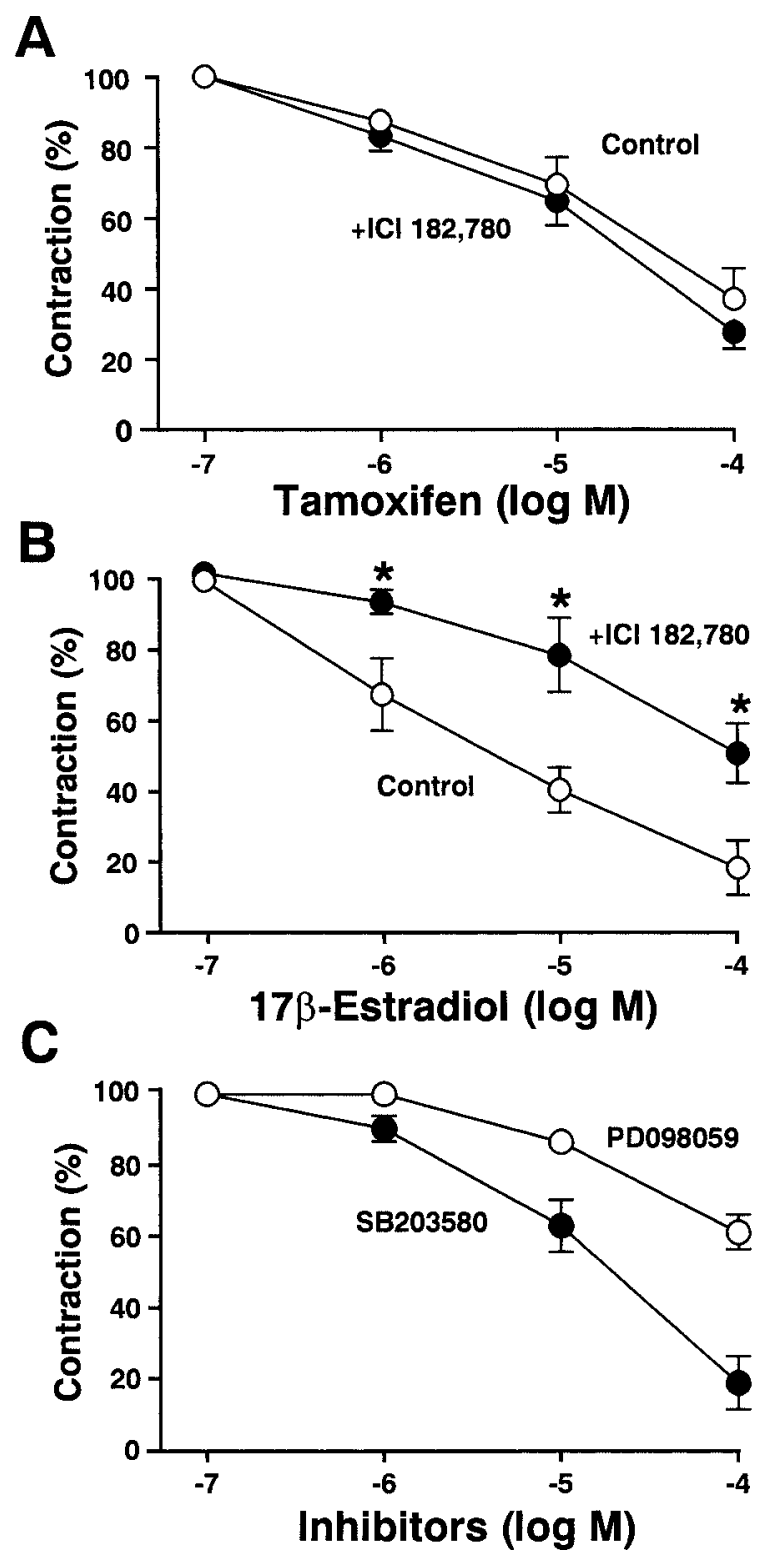

Fig. 2. Effects of tamoxifen and MAPK inhibitors on ET-1induced contraction in rat aortic smooth muscles. Muscle strips were pretreated without or with $10 \mu \mathrm{M}$ ICI 182,780 for $20 \mathrm{~min}$, and then contracted with $3 \mathrm{nM}$ ET-1. After ET-1induced contraction was confirmed, tamoxifen $(0.1-100 \mu \mathrm{M}$, A) and $17 \beta$-estradiol $(0.1-100 \mu \mathrm{M}, \mathrm{B})$ were added cumulatively. (C) The muscle strips contracted by $3 \mathrm{nM}$ ET- 1 were cumulatively treated with 0.1-100 $\mu \mathrm{M}$ PD098059, an inhibitor of MAPK/ERK kinase, or 0.1-100 $\mu \mathrm{M}$ SB203580, an inhibitor of p38 MAPK. The contractile level of ET-1 before the treatment with inhibitors was defined as $100 \%$. Each point represents the mean \pm S.E.M. of 5 experiments. $* P<0.05$ between control and ICI 182,780-treatment strips.

phosphorylated p38 MAPK antibody, was not altered by treatment with $100 \mu \mathrm{M}$ tamoxifen (Fig. 4A). 


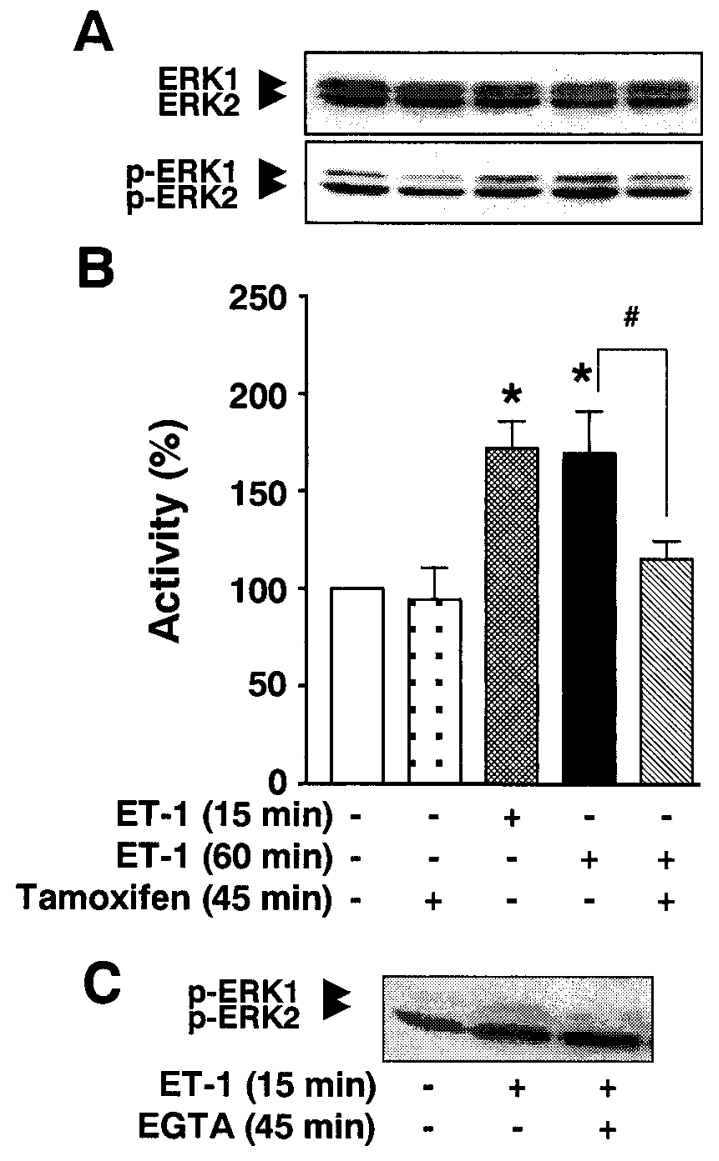

Fig. 3. Effects of tamoxifen on ET-1-induced ERK1/2 activity in rat aortic smooth muscle. Aortic strips were treated with 3 nM ET-1 for 15 min or $60 \mathrm{~min}$. Strips stimulated with ET-1 for 15 min were additively exposed to tamoxifen $(100 \mu \mathrm{M})$ or EGTA $(4 \mathrm{mM}$, panel C) for 45 min. Samples for Western blot analysis were prepared as described in "Materials and methods". The total expression and phosphorylation of ERK1/2 during the treatments were measured using anti-nonphosphorylated (upper panel) and anti-phosphorylated (lower panel) ERK1/2 antibodies, respectively. (B) Statistical results of levels of ERK1/2 phosphorylation in muscle strips were obtained from 4 independent experiments. The level of phosphorylated ERK1 plus ERK2 in the absence of ET-1 and tamoxifen was defined as $100 \%$. * $P<0.05$ versus control. \# $P<0.05$ between ET-1 and ET-1 plus tamoxifen. p-ERK, phosphorylated ERK.

\section{DISCUSSION}

In the present study, we showed that tamoxifen inhibited the contraction induced by ET-1 in rat aortic smooth muscle. Furthermore, we demonstrated that ET-1 stimulated both ERK1/2 and p38 MAPK activities and tamoxifen inhibited the MAPK activities. The inhibitors of MAPK/ERK kinase and p38 MAPK inhibited the contractile response in aortic smooth muscle, as was shown previously [9, 18], implying

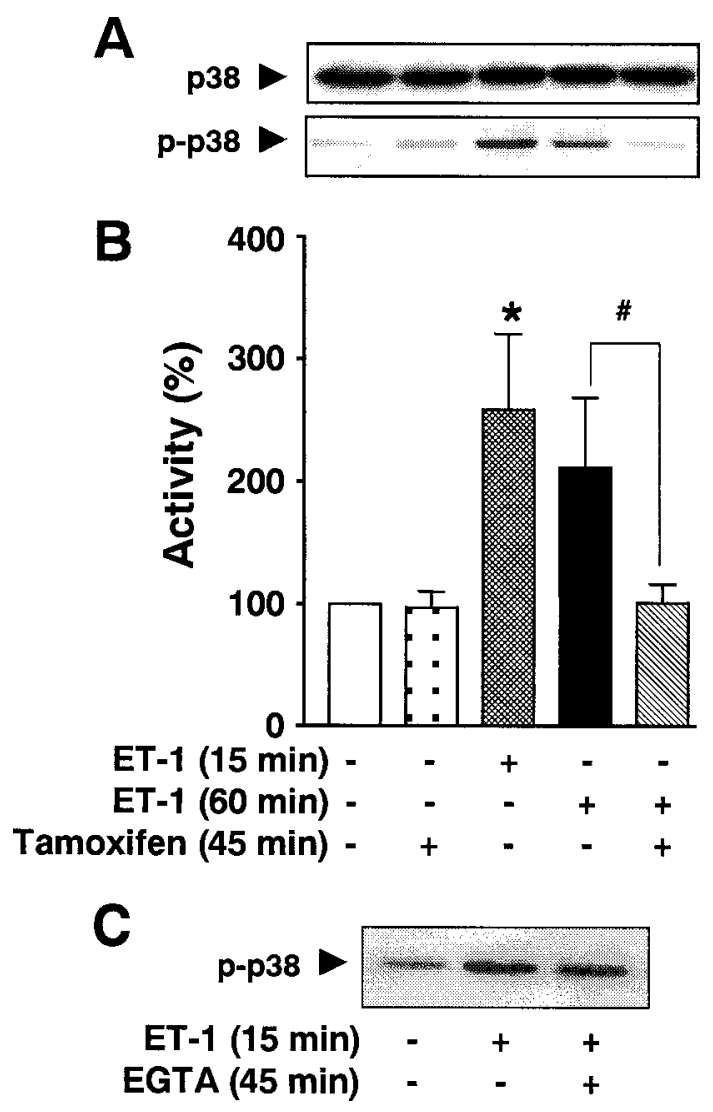

Fig. 4. Effects of tamoxifen on ET-1-induced p38 MAPK activity in rat aortic smooth muscle. The total expression and phosphorylation of p38 MAPK during the treatments were measured using anti-nonphosphorylated (upper panel) and anti-phosphorylated (lower panel) p38 MAPK antibodies, respectively. For further explanation, see legend to Fig. 3. (B) Statistical results were obtained from 4 independent experiments. p38, p38 MAPK; p-p38, phosphorylated p38 MAPK.

that p38 MAPK, as well as ERK1/2, participates in ET-1induced smooth muscle contraction $[1,7,11,19]$. Taken together, we concluded that the inhibiting effects of tamoxifen may be, at least in part, mediated by the inhibition of the MAPK pathways in vascular smooth muscle.

There are several reports that tamoxifen has an inhibitory effect on the contraction of vascular smooth muscle $[6,25$, 28]. Tamoxifen produces a direct reduction of inward $\mathrm{Ca}^{2+}$ currents through L-type $\mathrm{Ca}^{2+}$ channels in isolated smooth muscle cells [25]. In smooth muscle, the elevation of contraction is associated with the increases in $\left[\mathrm{Ca}^{2+}\right]_{\mathrm{i}}$ and MLC phosphorylation $[12,13,17]$. The inhibitory effects of tamoxifen on the $\mathrm{Ca}^{2+}$ current may contribute to the inhibition of the $\mathrm{Ca}^{2+} / \mathrm{MLCK} / \mathrm{MLC}$ phosphorylation pathway. In the present study, tamoxifen inhibited ET-1-induced contraction in the verapamil-pretreated muscle strips. The MAPK activity, both ERK1/2 and p38 MAPK, was not inhibited by the extracellular $\mathrm{Ca}^{2+}$ exclusion, implying that 
the activity is regulated by a $\mathrm{Ca}^{2+}$-independent mechanism. This result is consistent with the findings of an earlier study [15]. Moreover, it has been reported that PD098059 reduces vascular contraction induced by receptor agonists but not high-level $\mathrm{K}^{+}$[30]. Previously, we showed that MAPK is involved in smooth muscle contraction without the increment of MLC phosphorylation [19], which may result from activating heat shock protein and inhibiting the action of caldesmon $[8,33]$. Moreover, these molecules may participate to the $\mathrm{Ca}^{2+}$-sensitization, a $\mathrm{Ca}^{2+}$-independent contraction in smooth muscle [13]. These results suggest that tamoxifen may inhibit both $\mathrm{Ca}^{2+}$ entry through plasma membrane and $\mathrm{Ca}^{2+}$-independent MAPK pathway, resulting in the relaxation in vascular smooth muscle.

Epidemiological evidence suggests that tamoxifen has a protective effect on the cardiovascular system, which is similar to the effect of estrogen. The effect of tamoxifen on cardiovascular disease may partially depend on its direct effects on the relaxation of vascular smooth muscle [20]. In the present study, $17 \beta$-estradiol induced vasorelaxation by its non-genomic effect [27], and the inhibition was significantly recovered by treatment with the estrogen receptor antagonist ICI 182,780 [5]. Furthermore, estrogen also inhibited cell proliferation by inhibiting MAPK activity in vascular smooth muscle $[23,35]$. In contrast, the inhibition of contraction by tamoxifen was not reversed by the estrogen receptor antagonist. These results imply that tamoxifen induces vasorelaxation by a non-estrogen receptor pathway, although it may act on a similar site to estrogen, e.g., the MAPK pathway.

In conclusion, the present study showed that tamoxifen induces vasorelaxation and the inhibition of MAPK in rat aortic smooth muscle. Therefore, it has been suggested that tamoxifen-induced vasorelaxation may be, at least in part, mediated by the inhibition of MAPK in vascular smooth muscle.

ACKNOWLEDGMENT. This study was supported by Konkuk University Research Fund in 2000 and the Ministry of Science and Technology through the Bio-Food and Drug Research Center at Konkuk University, Choongju, Korea.

\section{REFERENCES}

1. Adam, L. P. and Hathaway, D. R. 1993. Identification of mitogen-activated protein kinase phosphorylation sequences in mammalian h-Caldesmon. FEBS Lett. 322: 56-60.

2. Anker, G., Lonning, P. E., Ueland, P. M., Refsum, H. and Lien, E. A. 1995. Plasma levels of the atherogenic amino acid homocysteine in post-menopausal women with breast cancer treated with tamoxifen. Int. J. Cancer 60: 365-368.

3. Cain, A. E., Tanner, D. M. and Khalil, R. A. 2002. Endothelin1 -induced enhancement of coronary smooth muscle contraction via MAPK-dependent and MAPK-independent $\left[\mathrm{Ca}^{2+}\right]_{\mathrm{i}}$ sensitization pathways. Hypertension 39: 543-549.

4. Dessy, C., Kim, I., Sougnez, C. L., Laporte, R. and Morgan, K. G. 1998. A role for MAP kinase in differentiated smooth muscle contraction evoked by alpha-adrenoceptor stimulation. Am. J. Physiol. 275: C1081-C1086.
5. Dubey, R. K., Jackson, E. K., Gillespie, D. G., Zacharia, L. C., Imthurn, B. and Keller, P. J. 2000. Clinically used estrogens differentially inhibit human aortic smooth muscle cell growth and mitogen-activated protein kinase activity. Arterioscler. Thromb. Vasc. Biol. 20: 964-972.

6. Figtree, G. A., Webb, C. M. and Collins, P. 2000. Tamoxifen acutely relaxes coronary arteries by an endothelium-, nitric oxide-, and estrogen receptor-dependent mechanism. J. Pharmacol. Exp. Ther. 295: 519-523.

7. Gerthoffer, W. T., Yamboliev, I. A., Pohl, J., Haynes, R., Dang, S. and McHugh, J. 1997. Activation of MAP kinases in airway smooth muscle. Am. J. Physiol. 272: L244-L252.

8. Hedges, J. C., Oxhorn, B. C., Carty, M., Adam, L. P., Yamboliev, I. A. and Gerthoffer, W. T. 2000. Phosphorylation of caldesmon by ERK MAP kinases in smooth muscle. Am. J. Physiol. 278: C718-C726.

9. Husain, S. and Abdel-Latif, A. A. 1999. Endothelin-1 activates p38 mitogen-activated protein kinase and cytosolic phospholipase A2 in cat iris sphincter smooth muscle cells. Biochem. J. 342: 87-96.

10. Hwang, K. C., Lee, K. H. and Jang, Y. 2002. Inhibition of MEK1,2/ERK mitogenic pathway by estrogen with antiproliferative properties in rat aortic smooth muscle cells. J. Steroid Biochem. Mol. Biol. 80: 85-90.

11. Ishihata, A., Tasaki, K. and Katano, Y. 2002. Involvement of p44/42 mitogen-activated protein kinases in regulating angiotensin II- and endothelin-1-induced contraction of rat thoracic aorta. Eur. J. Pharmacol. 445: 247-256.

12. Kamm, K. E. and Stull, J. T. 1985. The function of myosin and myosin light chain kinase phosphorylation in smooth muscle. Annu. Rev. Pharmacol. Toxicol. 25: 593-620.

13. Karaki, H., Ozaki, H., Hori, M., Mitsui-Saito, M., Amano, K., Harada, K., Miyamoto, S., Nakazawa, H., Won, K. J. and Sato, K. 1997. Calcium movements, distribution, and functions in smooth muscle. Pharmacol. Rev. 49: 157-230.

14. Katoch, S. S. and Moreland, R. S. 1995. Agonist and membrane depolarization induced activation of MAP kinase in the swine carotid artery. Am. J. Physiol. 269: H222-H229.

15. Kawanabe, Y., Hashimoto, N. and Masaki, T. 2002. Extracellular $\mathrm{Ca}^{2+}$ influx and endothelin-1-induced intracellular mitogenic cascades in rabbit internal carotid artery vascular smooth muscle cells. J. Cardiovasc. Pharmacol. 40: 307-314.

16. Khalil, R. A. and Morgan, K. G. 1993. PKC-mediated redistribution of mitogen-activated protein kinase during smooth muscle cell activation. Am. J. Physiol. 265: C406-C411.

17. Kim, B., Mitsui, M. and Karaki, H. 1992. The long-term inhibitory effect of a $\mathrm{Ca}^{2+}$ channel blocker, nisoldipine, on cytosolic $\mathrm{Ca}^{2+}$ and contraction in vascular smooth muscle. Eur. J. Pharmacol. 223: 157-162.

18. Kubo, T., Ibusuki, T., Saito, E., Kambe, T. and Hagiwara, Y. 2000. Different activation of vascular mitogen-activated protein kinases in spontaneously and DOCA-salt hypertensive rats. Eur. J. Pharmacol. 400: 231-237.

19. Kwon, S., Lee, W. J., Fang, L. H., Kim, B. and Ahn, H. Y. 2003. Mitogen-activated protein kinases partially regulate endothelin-1-induced contractions through a myosin light chain phosphorylation-independent pathway. J. Vet. Med. Sci. 65: $225-230$.

20. Lipton, A. 1987. The anti-oestrogen tamoxifen is a calcium antagonist in perfused rat mesentery. Cancer Chemother. Pharmacol. 20: 125-127.

21. Love, R. R., Barden, H. S., Mazess, R. B., Epstein, S. and Chappell, R. J. 1994. Effect of tamoxifen on lumbar spine bone 
mineral density in postmenopausal women after 5 years. Arch. Intern. Med. 154: 2585-2588.

22. Miyata, Y. and Nishida, E. 1999. Distantly related cousins of MAP kinase: biochemical properties and possible physiological functions. Biochem. Biophys. Res. Commun. 266: 291-295.

23. Morey, A. K., Pedram, A., Razandi, M., Prins, B. A., Hu, R. M., Biesiada, E. and Levin, E. R. 1997. Estrogen and progesterone inhibit vascular smooth muscle proliferation. Endocrinology 138: 3330-3339.

24. Ohanian, J., Cunliffe, P., Ceppi, E., Alder, A., Heerkens, E. and Ohanian, V. 2001. Activation of p38 mitogen-activated protein kinases by endothelin and noradrenaline in small arteries, regulation by calcium influx and tyrosine kinases, and their role in contraction. Arterioscler. Thromb. Vasc. Biol. 21: 1921-1927.

25. Ratz, P. H., McCammon, K. A., Altstatt, D., Blackmore, P. F., Shenfeld, O. Z. and Schlossberg, S. M. 1999. Differential effects of sex hormones and phytoestrogens on peak and steady state contractions in isolated rabbit detrusor. J. Urol. 162: 1821-1828.

26. Saarto, T., Blomqvist, C., Ehnholm, C., Taskinen, M. R. and Elomaa, I. 1996. Antiatherogenic effects of adjuvant antiestrogens: a randomized trial comparing the effects of tamoxifen and toremifene on plasma lipid levels in postmenopausal women with node-positive breast cancer. J. Clin. Oncol. 14: 429-433.

27. Salom, J. B., Burguete, M. C., Perez-Asensio, F. J., Torregrosa, G. and Alborch, E. 2001. Relaxant effects of $17 \beta$-estradiol in cerebral arteries through $\mathrm{Ca}^{2+}$ entry inhibition. J. Cereb. Blood Flow Metab. 21: 422-429.

28. Song, J., Standley, P. R., Zhang, F., Joshi, D., Gappy, S., Sow- ers, J. R. and Ram, J. L. 1996. Tamoxifen (estrogen antagonist) inhibits voltage-gated calcium current and contractility in vascular smooth muscle from rats. J. Pharmacol. Exp. Ther. 277: 1444-1453.

29. Touyz, R. M., El Mabrouk, M., He, G., Wu, X. H. and Schiffrin, E. L. 1999. Mitogen-activated protein/extracellular signalregulated kinase inhibition attenuates angiotensin II-mediated signaling and contraction in spontaneously hypertensive rat vascular smooth muscle cells. Circ. Res. 84: 505-515.

30. Watts, S. W. 1996. Serotonin activates the mitogen-activated protein kinase pathway in vascular smooth muscle: use of the mitogen-activated protein kinase inhibitor PD098059. J. Pharmacol. Exp. Ther. 279: 1541-1550.

31. Widmann, C., Gibson, S., Jarpe, M. B. and Johnson, G. L. 1999. Mitogen-activated protein kinase: conservation of a three-kinase module from yeast to human. Physiol. Rev. 79: 143-180.

32. Wiseman, H. 1995. Tamoxifen as an antioxidant and cardioprotectant. Biochem. Soc. Symp. 61: 209-219.

33. Yamboliev, I. A., Hruby, A. and Gerthoffer, W. T. 1998. Endothelin-1 activates MAP kinases and c-Jun in pulmonary artery smooth muscle. Pulm. Pharmacol. Ther. 11: 205-208.

34. Yamboliev, I. A., Hedges, J. C., Mutnick, J. L., Adam, L. P. and Gerthoffer, W. T. 2000. Evidence for modulation of smooth muscle force by the p38 MAP kinase/HSP27 pathway. Am. J. Physiol. 278: H1899-H1907.

35. Zhang, L., Li, B., Zhao, W., Chang, Y. H., Ma, W., Dragan, M., Barker, J. L., Hu, Q. and Rubinow, D. R. 2002. Sex-related differences in MAPKs activation in rat astrocytes: effects of estrogen on cell death. Mol. Brain Res. 103: 1-11. 